NIPER-548

Distribution Category LC-122

Modeling and Laboratory Investigations of

NIPER --548

Microbial Transport Phenomena in Porous Media

DE92 001003

Topical Report

By

Ming-Ming Chang

Rebecca S. Bryant

Ting-Horng Chung

Hong W. Gao

November 1991

Work Performed Under Cooperative Agreement No. FC22-83FE60149

Prepared for

U.S. Department of Energy

Assistant Secretary for Fossil Energy

Fred Burtch, Project Manager

Bartlesville Project Office

P. O. Box 1398

Bartlesville, OK 74005

Prepared by

IIT Research Institute

Vationa Institute for Petroleum and Energ. Research

P. O. Box 2128

Bartiesvilie. OK 7005

MASTER 


\section{TABLE OF CONTENTS}

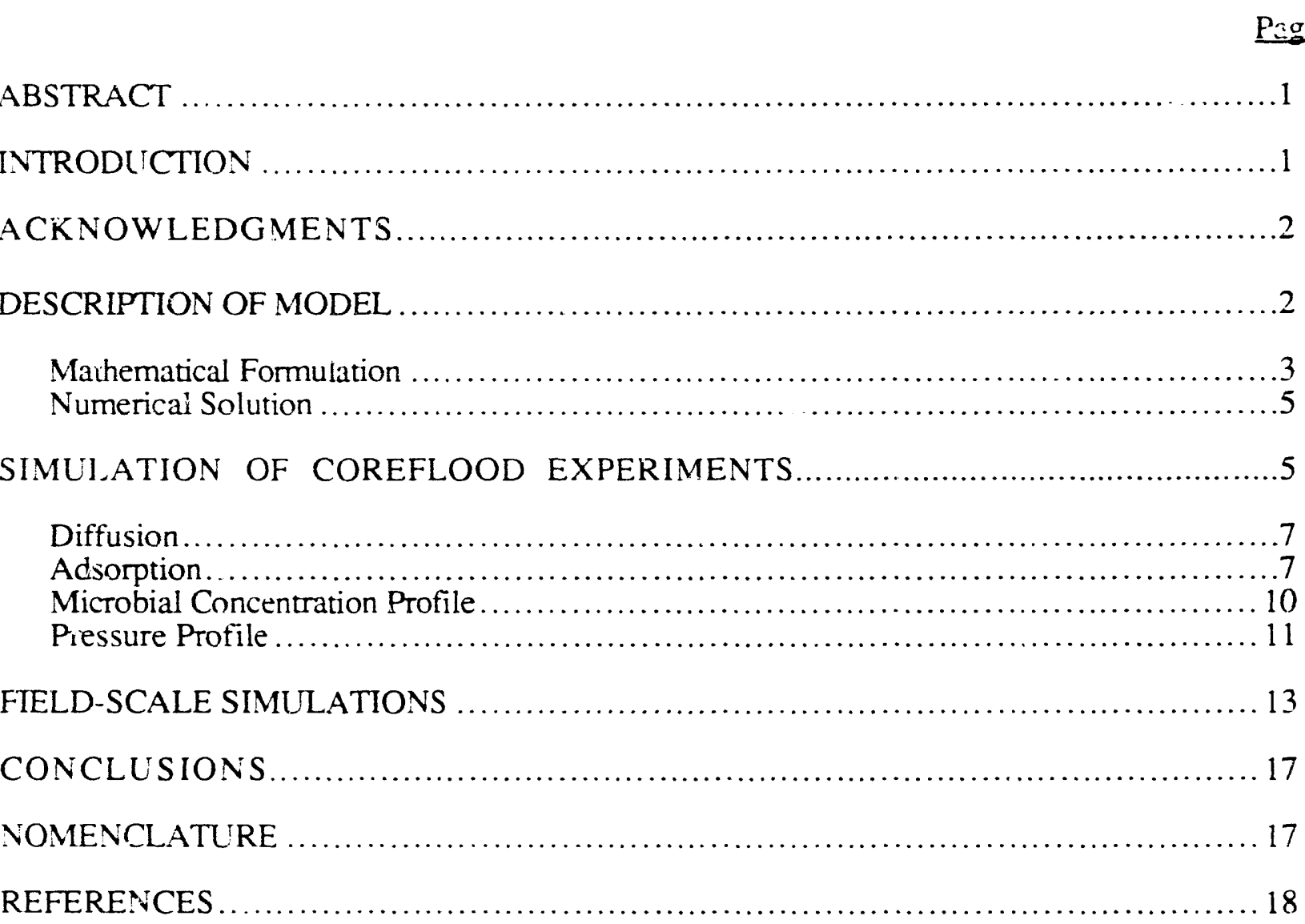

\section{TABLES}

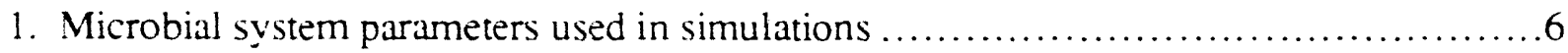

2. Core properties and microbial system parameters used in matching microbial effluent prnfiles

3. Core properties and microbial system parameters used in simulating microbial and nutrient concentration profiles

4. Core properties and microbial system parameters used in matching pressure drop in microbial corefloods

5. Reservoir model and microbial system parameters used in field-scale simulations 


\section{ILLUSTRATIONS}

Page

1. Microbial concentration and sugar consumption in a flask test. .......................6

2. Simulation match of experimental tracer data in a 4-ft-long Berea sandstone core. ........7

3a. Simulation match of the microbial concentration in coreflood $\ldots \ldots \ldots \ldots \ldots \ldots \ldots \ldots \ldots$

3b. Simulation match of the microbial concentration in coreflood .........................9

3c. Simulation match of the microbial concentration in coreflood ........................... 9

4. Results of simulation of the nutrient and microbial concentration profiles .............. 10

5. Simulation match of pressure drop and porosity change in a microbial coreflood......... 13

6. Microbial profiles for reservoirs with various clogging rate constants....................... 14

7. Effect of chemotaxis coefficient $k_{\mathrm{ch}}$ on microbial concentration profile. ............... 15

8. Fractional injection into low-permeability layer............................................. 16

9. Injection profile modification using microbial treatment.............................. 16 


\title{
MODELING AND L.ABORATORY INVESTIGATIONS OF MICROBIAL TRANSPORT PHENOMENA IN POROUS MEDIA
}

\author{
By Ming-Ming Chang, Rebecca S. Bryant, Ting-Horng Chung, and Hong W. Gao
}

\begin{abstract}
Simulation and experimental results on the transport of microbes and nutrients in onedimensional cores are presented, and the development of a three-dimensional, three-phase, multiple-component numerical model to describe the microbial transport phenomena in porous media is described. The governing equations in the mathematical model include net flux of microbes by convection and dispersion, decay and growth rates of microbes, chemotaxis and nutrient consumption, and deposition of microbes on rock grain surfaces. Porosity and permeability reductions due to cell clogging have been considered, and the production of gas by microbial metabolism has been incorporated. Governing equations for microbial and nutrient transport are coupled with continuity and flow' equations under conditions appropriate for a black oil reservoir.

The computer simulator has been used to determine the effects of various transport parameters on microbial transpor phenomena. The model can accurately describe the observed transport of microbes. nutrients, and metabolites in coreflooding experiments. Input parameters are determined by matching laboratory experirnental results. The model can be used to predict the propagation of microbes and nutrients in a model reservoir and to optimize injection strategies. Optimization of injection strategy results in increased oil recovery due to improvements in sweep efficiency.
\end{abstract}

\section{INTRODLCTION}

Microbial methods for increasing oil recovery are potentially cost-effective even at relatively low crude oil prices. Microbial formulations can be applied in a variety of methods including permeability modification treatments and microbial-enhanced waterflooding. ${ }^{1-3}$ The flexibility and potential cost-effectiveness of the technology make it attractive, but further understanding of the transport mechanisms of microorganisms and the development of a sound engineering methodology for optimizing microbial formulations and injection strategies are needed to realize its potential. 
The transport of microorganisms (bacteria, fungi, and viruses) in porous media governs many phenomena in bioremediation of environmental pollution problems and microbial enhanced oil recovery (MEOR). The purpose of this study was to investigate the effects of transport parameters of microbes to modify reservoir heterogeneities and improve oil recovery. The transport of microorganisms in subsurface formations is governed by many complicated physical, chemical, and biological phenomena such as adsorption, interaction between microorganisms and substrate, and growth and decay of cells. ${ }^{4-8}$ Information concerning the transport, growth, and metabolism of viable cells in subsurface environments is scarce, and some of the phenomena are still not well understood.

Although several attempts have been made to describe microbial processes, ${ }^{9-11}$ no model has yet fully incorporated all of the complex phenomena that are believed to be important. The unusual complexity of oil recovery by microbial formulations requires close coordination between laboratory mechanistic studies and oil displacement experiments under carefully controlled conditions to develop and validate a computer model. The accuracy of a simulator that is designed for MEOR processes will be strongly dependent upon the accuracy of the equations that ire used to describe the important phenomena. An accurate reservoir simulator for MEOR methods can best be developed through an integrated program of acquisition of laboratory and field data with the feedback loop being the reservoir simulation model. This report describes the development of a three-dimensional, three-phase, multiple-component numerical model, with the input of laboratory investigations, to describe microbial transport phenomena in porous media.

\section{ACKNOWLEDGMENTS}

This research was funded by the Department of Energy under cooperative agreement DE-FC22-83FE60149. The authors thank Dr. Fred W. Burtch and Edith Allison of the Department of Energy Bartlesville Project Office for their encouragement and support in conducting this work and Dr. Thomas E. Burchfield and Dr. Min K. Tham of NIPER for their suggestions in the preparation of this report.

\section{DESCRIPTION OF MODEL}

Mathematical models for microbial transport processes were developed in two steps. The first step was to develop a mathematical model to predict the propagation and distribution of microorganisms and nutrients in porous media. This transport model accounts for physical phenomena that affect the transport of microbial systems such as diffusion, adsorption, growth and decay of microorganisms, and consumption of nutrients. Porosity reduction and permeability 
changes due to cell clogging have been considered in this model. This model can be used to predict the concentration distributions for injected nutrients and microc-ganisms with various injection modes at either field or laboratory scale.

The second step was to incorporate the transport equations for microurjanisms and microbial nutrients into a three-dimensional, three-phase (oil, water, and gas) black oil simulator. Distributions of pressure and oil/water/gas saturation in porous media were solved from the continuity equation. The Darcy flow velocity due to the pressure gradient in porous media was then used in the transport calculation for microorganisms and microbial nutrients. Using this simulator, the transport of microorganisms can be investigated, and the effect of a microbial system. on oil recovery can be studied.

\section{Mathemaícal Formulation}

The microbial transport in porous media is described by the following equations: ${ }^{4}$

$$
\begin{gathered}
\vec{\nabla} \cdot \overrightarrow{\vec{D}} \cdot \vec{\nabla}(\phi S C)-\vec{\nabla} \cdot(\overrightarrow{\mathrm{u} C})-\mathrm{k}_{\mathrm{m}} \vec{\nabla} \cdot\left(\mathrm{C} \vec{\nabla} \ln \mathrm{C}_{\mathrm{f}}\right)+\phi \mathrm{S}\left(\mu-\mathrm{k}_{\mathrm{d}}\right) \mathrm{C} \\
+\mathrm{QC} / \mathrm{V}=\frac{\partial(\phi S \mathrm{C})}{\partial \mathrm{t}}+\phi S \mathrm{k}_{\mathrm{c}} \mathrm{C}-\mathrm{k}_{\mathrm{y}} \rho \sigma\left(\frac{\sigma}{\phi}\right)^{\mathrm{h}}
\end{gathered}
$$

where $\sigma$ is solved from

$$
\frac{\partial \sigma}{\partial t}=\left(\mu-k_{d}\right) \sigma+k_{c} \frac{\phi S C}{\rho}-k_{y} \sigma\left(\frac{\sigma}{\phi}\right)^{h}
$$

The five terms on the left-hand side of Eq. 1 correspond to the dispersion, convection, chemotaxis, growth and decay, and injection/production of microbes, respectively. The right-hand side of Eq. 1 shows the accumulation, clogging, and declogging of microbes in the aqueous phase. Equation 2 describes the growth, decay, clogging, and declogging of microbes on the rock. surface.

The growth of microbes, $\mu$, was assumed to follow the Monod equation: 12

$$
\mu=\frac{\mu_{m} C_{f}}{K_{s}+C_{f}}
$$


where $\mu_{m}$ is the maximum growth rate achievable and $K_{s}$ is that value of the concentration of the substrate where the specific growth rate has half its maximum value. Values of $\mu_{m}$ and $K_{s}$ can be obtained from experimental results. The decay rate was assumed to be a first-order reaction.

The deposition of microbes is determined by clogging and declogging mechanisms as expressed in the last two terms in Eq. 1. The clogging rate is assumed to be proportional to the microbial concentration. The power term in the declogging term dictates the desorption rate of microbes as a function of adsorption saturation on rock surface. ${ }^{4}$ The chemotactic flow of microbes, which was induced by the presence of nutrients, was assumed to follow an exponential gradient of nutrient concentration. ${ }^{4-5}$ The change of porosity of the porous medium was accounted by the deposition of microbes:

$$
\phi=\phi_{0}-\sigma
$$

where $\phi_{0}$ is the original porosity of the porous medium. The permeability reduction due to the deposition of microorganisms to the rock pore space was assumed to follow: ${ }^{13}$

$$
\log (k)=a_{0}+a_{1} \cdot(\phi)
$$

where $\mathrm{a}_{0}$ and $\mathrm{a}_{1}$ are experimentally determined constants.

The transport of nutrient is described by the following equation: ${ }^{4}$

$$
\vec{\nabla} \cdot \overrightarrow{\vec{D}}_{f} \cdot \vec{\nabla}\left(\phi S C_{f}\right)-\vec{\nabla} \cdot\left(\vec{u}_{f}\right)-\mu(\phi S C+\rho \sigma) / \mathrm{Y}+\mathrm{QC}_{\mathrm{f}} / \mathrm{V}=\frac{\partial\left(\phi S C_{\mathrm{f}}\right)}{\partial \mathrm{t}}
$$

Shown on the left-hand side of Eq. 6, the dispersion, convection, consumption, and injection/production terms of nutrient make up the nutrient transport equation in the aqueous phase. The yield coefficient $Y$ is defined as the mass of cells produced per unit of substrate removed. Equation 1 is coupled with Eq. 6 in solving concentration distributions of microbes and nutrients.

The flux terms in transport Eqs. 1 and 6 are solved from three-dimensional, three-phase continuity equations applicable in an environment of black oil reservoirs. ${ }^{14}$ The continuity equations are given by:

$$
\left.-\vec{\nabla} \cdot\left(\frac{\rho_{\vec{u}}}{B}\right)_{m}-Q_{m}=\frac{\partial}{\partial t} \mid \frac{\phi \rho S}{B}\right)_{m}
$$

where $\mathrm{m}=$ oil, water, or gas phase. 
Sources (injectors) and sinks (producers) at various strengths are assigned through well rates (Q) in the model. The gas produced from metabolism of a microbial system is taken into account in the model also through the term of $Q$ in Eq. 7.

\section{Numerical Solution}

The fluid flow (Eq. 7) is solved for Darcy velocity using an IMPES procedure. A no-flow boundary of the reservoir is implemented by setting pressure gradient at boundary interfaces to zero. This is followed by the solution of transport equations of microbes (Eq. 1) and nutrients (Eq. 6). The Crank-Nicolson method ${ }^{15}$ was used in formulating the finite difference form of transport equations. Both microbial and nutrient concentrations were solved implicitly in space using a direct solution method for the sparse matrix. The amount of deposition of microorganisms was then calculated, and the permeability was adjusted for pressure calculations in the next time step.

\section{SIMULATION OF COREFLOOD EXPERIMENTS}

Parameters of the microbial transport system were determined from laboratory experiments or from simulation matches of laboratory tests using the developed mathematical model. The laboratory experiments included microbial coreflood tests and flask tests.

Fig. 1 shows the microbial growth and nutrient consumption from a flask test. The population of the microbial system used, designated NIPER 6, grew to $10^{6}$ times within 20 hours at a full supply of nutrients in a flask. This is equivalent to a maximum growth rate of 8.4 day $^{-1}$. The decay rate constant, determined from the population change during the period of 200 to 600 hours in Fig. 1, is 0.22 day $^{-1}$. The cell yield coefficient, Y, of 0.5 is computed from the nutrient consumption rate.

To determine model parameters, mathematical simulations were performed to match coreflood tests of diffusion, adsorption, concentration profiles, and pressure profiles. The core model was dimensioned at $50 * 1 * 1$ in simulation runs. The relative permeability values were determined from a microbial coreflood $i$. the laboratory. ${ }^{16}$ Table 1 lists part of the microbial system parameters used in the following laboratory and field scale simulations. 


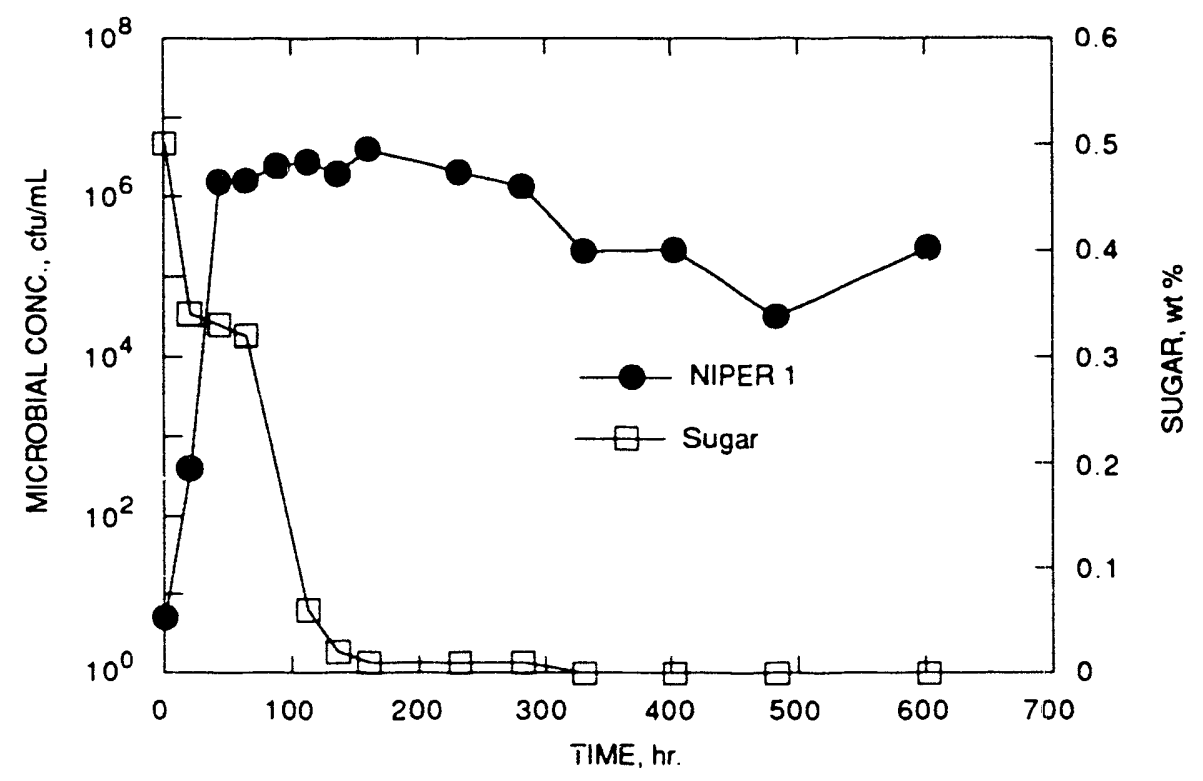

FIGURE 1. - Microbial concentration and sugar consumption in a flask test.

TABLE 1. Microbial system parameters used in simulations

Diffusion coefficient

microbes, $\mathrm{ft}^{2} /$ day

0.0055

nutrient, $\mathrm{ft}^{2} /$ day 0.0083

Declogging rate constant, day ${ }^{-1}$ 37.

Declogging parameter 0

Cell yield coefficient $(\mathrm{Y})$ 0.5

Monod half growth constant, $\mathrm{lb} / \mathrm{cu} \mathrm{ft}$. 0.5

Maximum growth rate, day ${ }^{-1}$ 8.4

Decay rate, day ${ }^{-1}$ 0.22

Chemotaxis coefficient 0 


\section{Diffusion}

A tracer coreflood test was matched in Fig. 2 using a diffusion coefficient of $8.93 \mathrm{E}-5 \mathrm{~cm}^{2} / \mathrm{sec}$ or $8.3 \mathrm{E}-3 \mathrm{ft}^{2} / \mathrm{day}$. A total of 0.2 pore volume of $50 \mathrm{ppm}$ fluorescein tracer was injected into the 4 - $\mathrm{ft}$-long Berea sandstorie core at a rate of $0.73 \mathrm{ft} /$ day. More than $99 \%$ of tracer was recovered from this coreflood test.

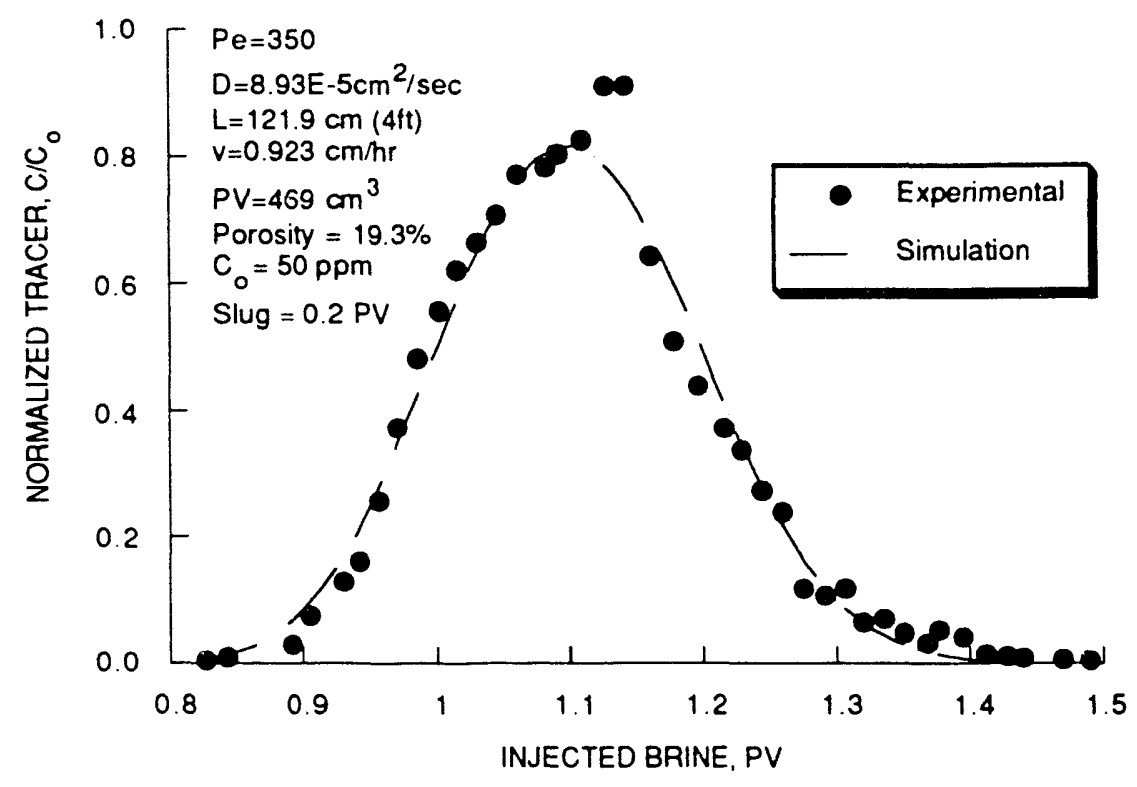

FIGURE 2. - Simulation match of experimental tracer data in a 4-ft-long Berea sandstone core.

\section{Adsorption}

The concentration profiles of microbial coreflood effluents were matched for a total of four coreflood tests to determine clogging and declogging rate constants. In the four coreflood tests, microbes were introduced at four different pore volumes: $0.25,0.75,1.0$, and 1.5 , respectively. Virtually no microbes were recovered in the coreflood effluent at a microbial injection of 0.25 pore volume. The microbial concentration in the effluents increased with the increase of microbial injection from 0.75 to 1.5 pore volumes. These tests showed an irreversible clogging or adsorption until $0.3 \%$ bulk volumes of pore space were deposited by microbes. Values of 25 and 37 day $^{-1}$ were determined for clogging and declogging rates, respectively, from matches of microbial effluents of four coreflood tests. Figs. 3a through $3 \mathrm{c}$ show these simulation matches for 
experimental injections of $0.75,1.0$, and 1.5 pore volumes of microbes, respectively. Input parameters for matching the coreflood test that used 1.5 pore volumes of microbial injection are listed in Table 2.

TABLE 2. Core properties and microbial system paramciers used in matching microbial effluent profiles

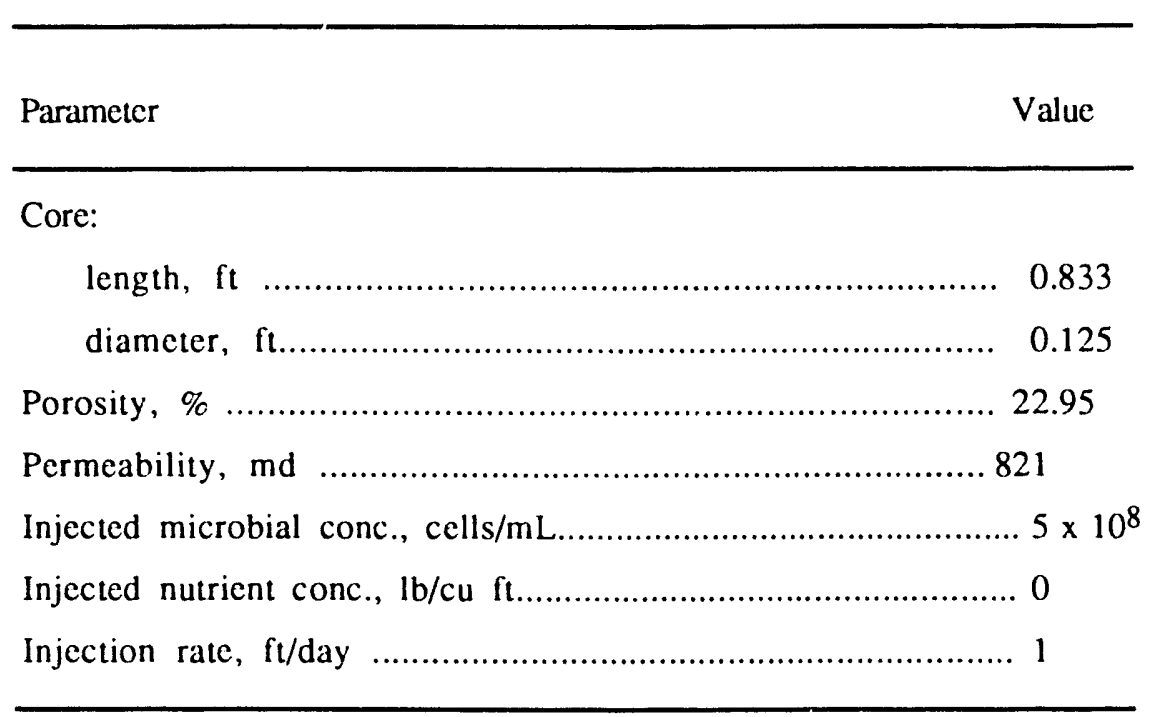

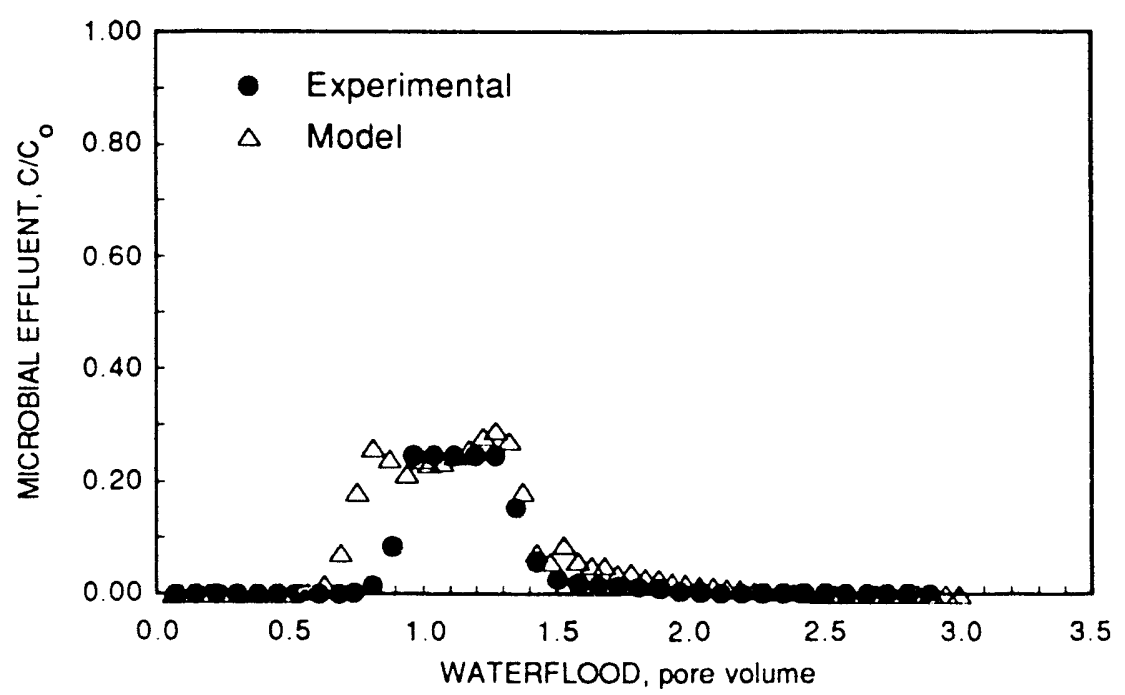

FIGURE 3a. - Simulation match of the microbial concentration in coreflood effluent after $0.75 \mathrm{PV}$ injection. 


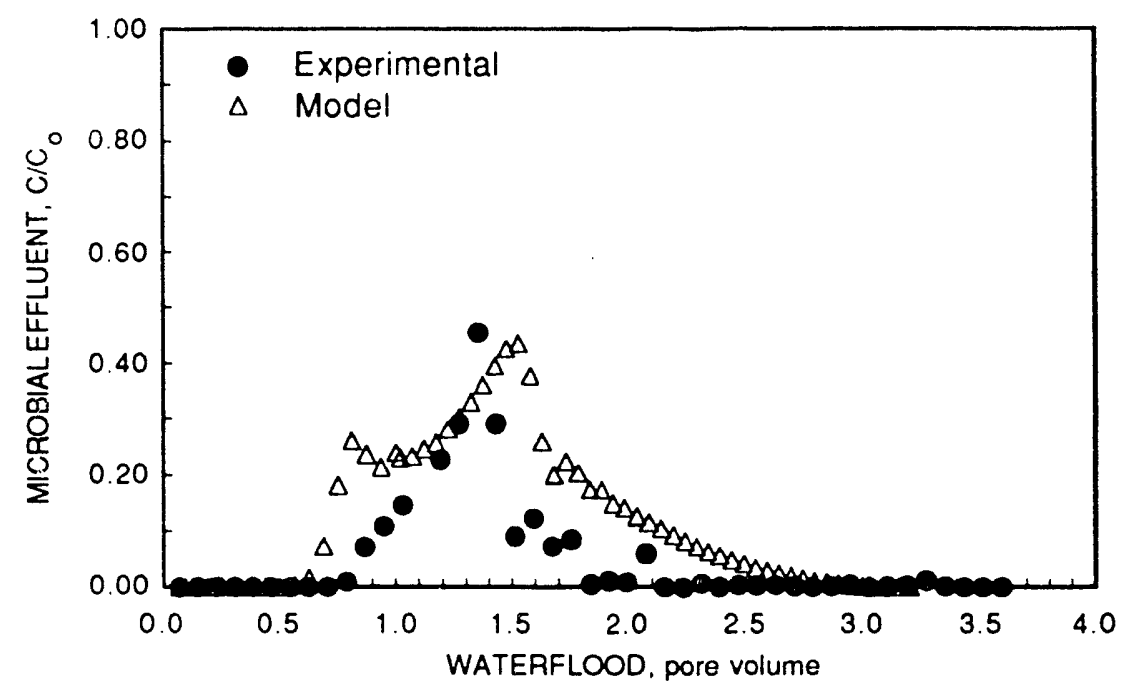

FIGURE 3b. - Simulation match of the microbial concentration in coreflood effluent after 1.0 PV injection.

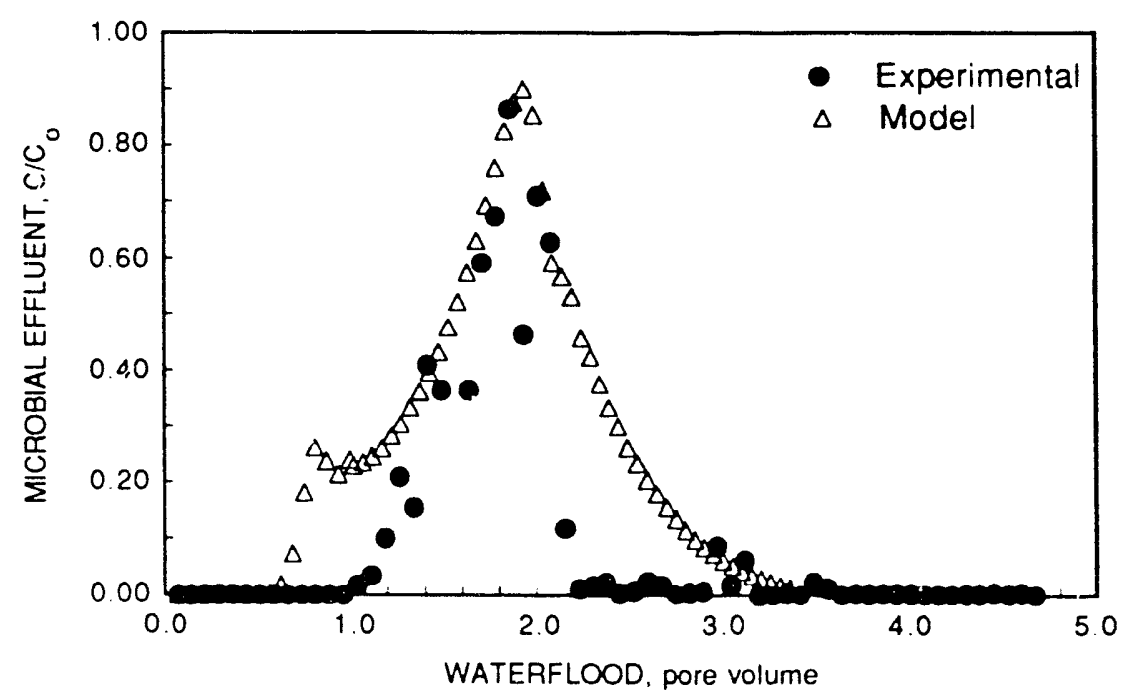

FIGURE 3c. - Simulation match of the microbial concentration in coreflood effluent after 1.5 PV injection. 


\section{Microbial Concentration Profile}

One microbial/nutrient coreflood experiment was conducted in a 4-ft-long core. The core was injected with 0.05 pore volume of nuirient ( $4 \mathrm{wt} \%$ molasses) followed by injections of 0.1 pore volume of microties and 0.05 pore volume of nutrient. The core was then incubated (shut-in) for 3 days and injected with 0.1 pore volume of nutrient. The core was shut in for another 3 days before the initiation of waterflood. The microbial concentrations were monitored from the four ports which were $0.5,1.5,2.5$, and $3.8 \mathrm{ft}$, respectively, from the injection end of the core. Fig. 4 snows the sim lation results of microbial and nutrient concentrations at 0.5 pore volume of waterflood. The core properties and microbial/nutrient parameters are listed in Table 3.

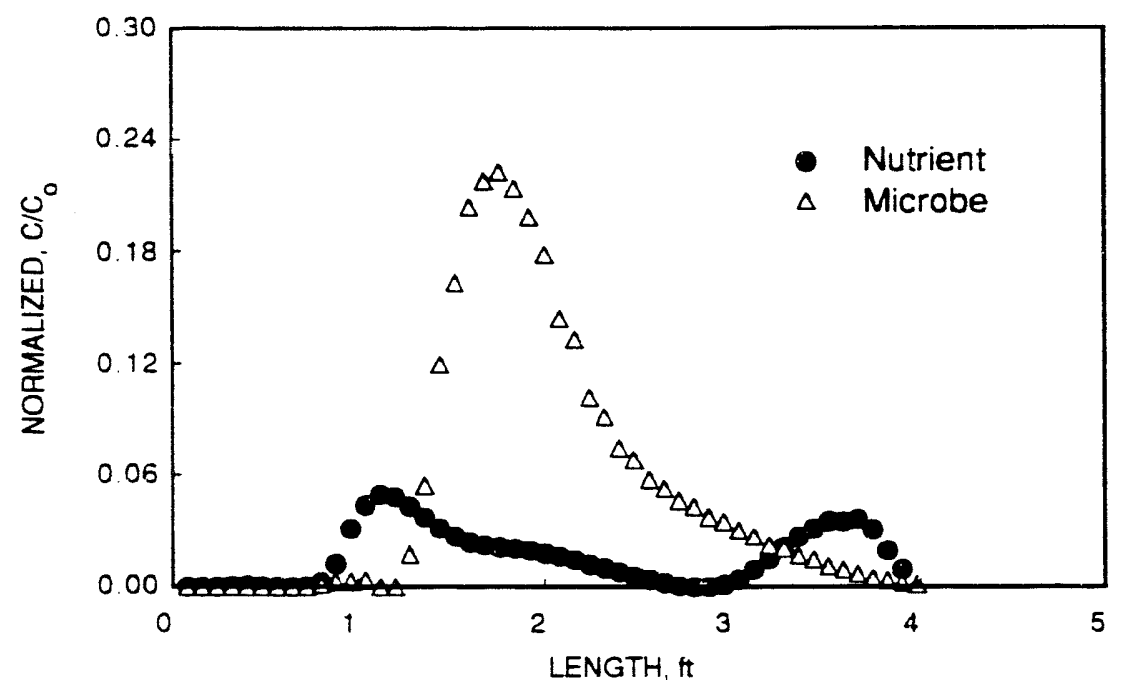

FIGURE 4. - Results of simulation of the nutrient and microbial effluent concentraiion profiles through a 4-ft long Berea sardstone core after 0.5 PV waterflood. 
TABLE 3. Core properties and microbial system parameters used in simulating microbial and nutrient concentration profiles

\begin{tabular}{|c|c|}
\hline Parameter & Value \\
\hline \multicolumn{2}{|l|}{ Core: } \\
\hline length, $\mathrm{ft} \ldots \ldots \ldots \ldots \ldots \ldots \ldots \ldots$ & 4.0 \\
\hline diameter, ft....... & 0.167 \\
\hline Porosity, \% .................... & 17.1 \\
\hline 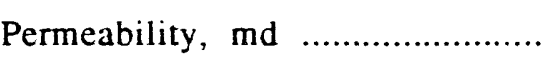 & 64.8 \\
\hline Initial oil saturation, $\% \ldots \ldots \ldots$. & 28.8 \\
\hline 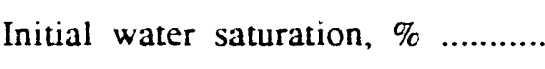 & 71.2 \\
\hline Injected microbial conc., cells $/ \mathrm{mL}$ & $5 \times 10^{8}$ \\
\hline Injected nutrient conc., $\mathrm{lb} / \mathrm{cu} \mathrm{ft}$..... & 2.5 \\
\hline Injection rate, $\mathrm{ft} / \mathrm{day} \ldots \ldots \ldots \ldots \ldots$ & 1 \\
\hline
\end{tabular}

\section{Pressure Profile}

A pressure profile from a microbial coretlood test was matched in the simulation run. In the coreflood test, 0.1 pore volume of microbial solution was introduced into the core. This was followed by an injection of 0.2 pore volume of nutrient solution and 3 days of shut-in. After the shut-in, another 0.2 pore volume of nutrient solution was injected and followed by waterflood at $1 \mathrm{ft} /$ day. The profile of pressure drop across the core during the brine injection was monitored and is shown in Fig. 5, together with the modeling match and the calculated profile of porosity change due to clogging and declogging reactions. A published value ${ }^{13}$ of 25.2 for permeability-porosity coefficient $a_{1}$ in Eq. 5 was used in the model to account for the permeability reduction caused by microbial deposition. A biogenic gas production rate of $30 \mathrm{~mL}$ per gram of nutrient consumption, which was measured from a separate test, was used in the simulation. Table 4 lists values of parameters used in the simulation match. 


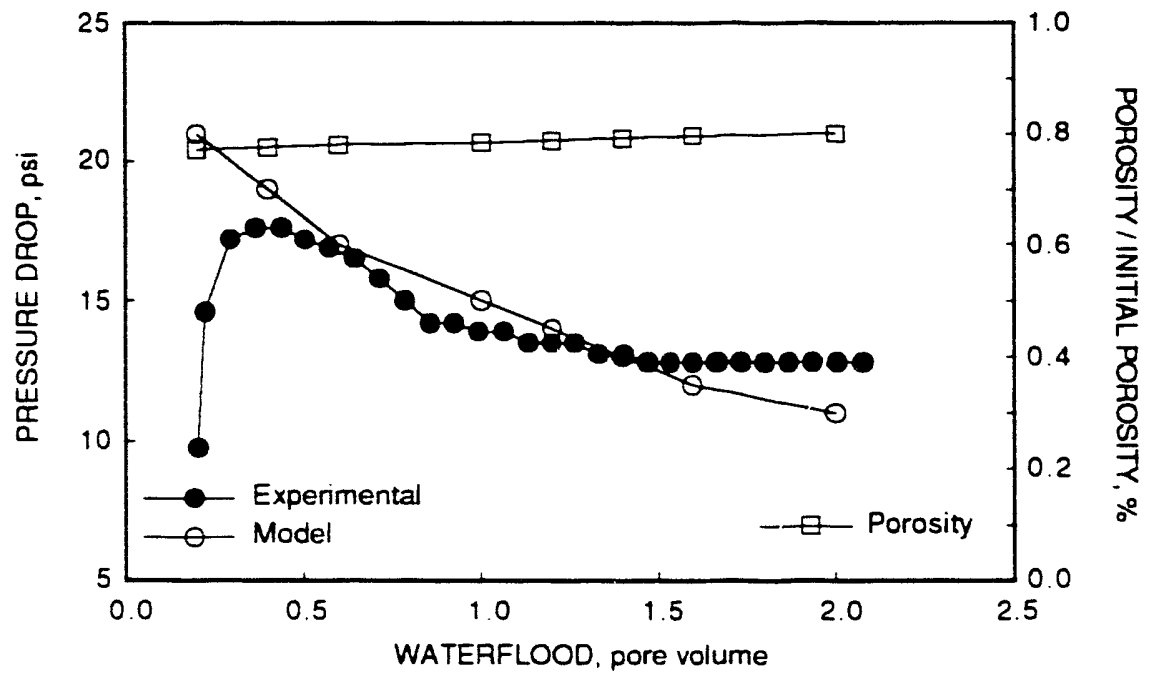

FIGURE 5. - Simulation match of pressure drop and porosity change in a microbial coreflood.

TABLE 4. Core properties and microbial system parameters used in matching pressure drop in microbial coreflood

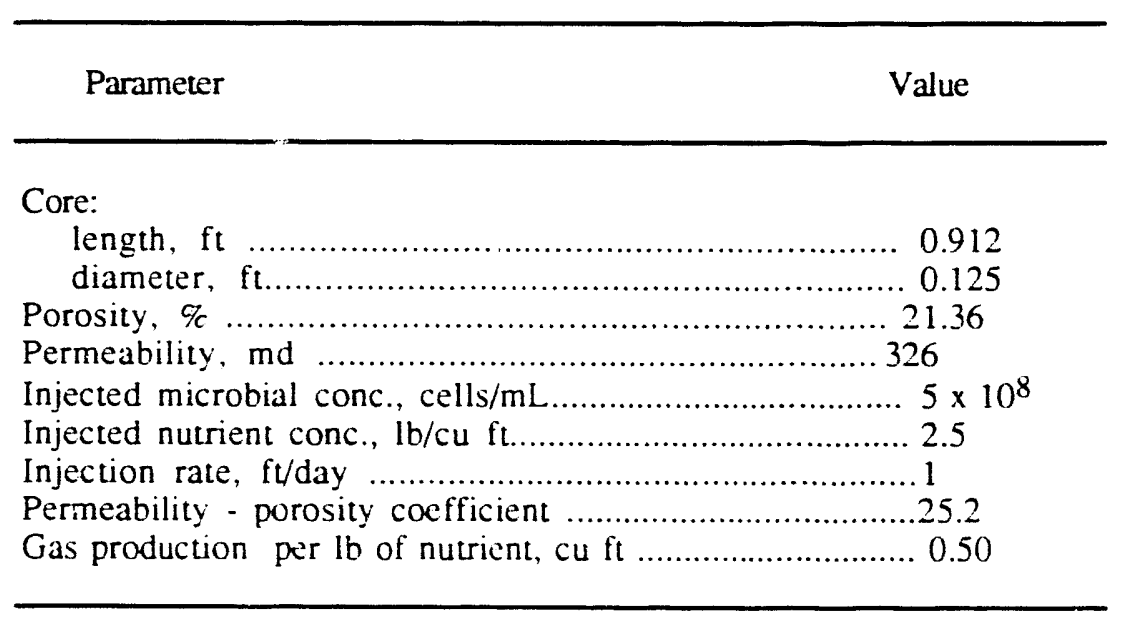

The initial pressure drop during waterflooding before the microbial treatment was 1.5 psi. The simulation results showed that the sharp increase of pressure drop after the microbial flooding is caused by pore plugging and the nroduction of biogenic gas. The pore plugging reduces the rock permeability, and the increase of gas saturation decreases the relative permeability of the water phase. As the waterflood proceeds, the permeability (or porosity) recovers slightly (Fig. 5) with the declogging of microbes in the pore space; therefore, a decrease in pressure drop was observed from the coreflood. 


\section{FIELD-SCAIE SIMULATIONS}

Field-scale simulation runs were conducted to study the microbial transport in reservoirs using the developed microbial simulator. Effects of clogging and chemotaxis on microbial transport were simulated in a one-dimensional reservoir model. The feasibility of applying the microbial system for modifying injection profiles from a wellbore was investigated in a twodimensional cross section model. Table 5 shows the reservoir model and the microbial parameters used in simulations. In the one-dimensional simulation run, only the top layer was used as the reservoir model. Injection rates used were $100 \mathrm{bbl} /$ day in the one-dimensional simulation runs and $300 \mathrm{bbl} /$ day in the two-dimensional simulation runs. Injection sequence and sizes of the slugs in each simulation run are shown in Figs 6 through 9.

TABLE 5. Reservoir model and microbial system parameters used in fieldscale simulations

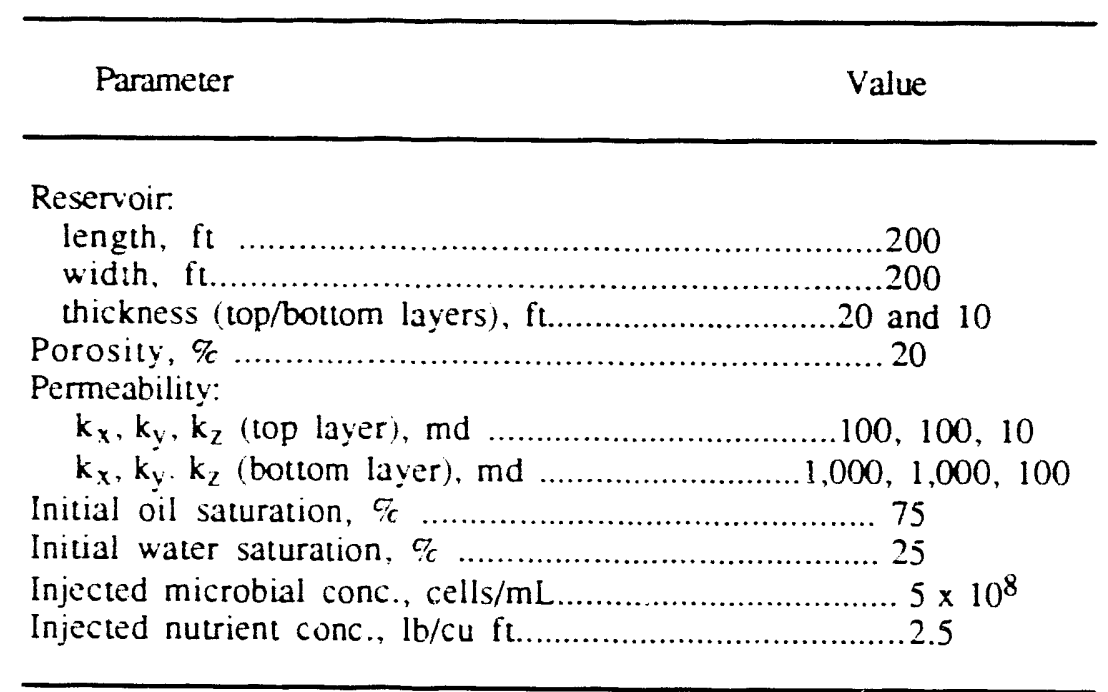

The clogging or adsorption of microorganisms to the rock surface was found to be critical to the transport of microbes in reservoirs from simulation results. Fig. 6 shows concentration profiles of microbes in formations with three different clogging parameters: 0.1 , and 25 day $y^{-1}$, respectively. The microbial slug penetrates $70 \mathrm{ft}$ into the formation when the clogging reaction is absent or $k_{c}$ is equal to 0 . Thic penetration depth of microbes is reduced to $30 \mathrm{ft}$ when $k_{c}$ is 1 da $y^{-1}$ and a much smaller microbial slug is found to move away from the wellbore when $k_{c}$ is increased to $25 \mathrm{day}^{-1}$ due to loss of microorganisms to the rock surface. 


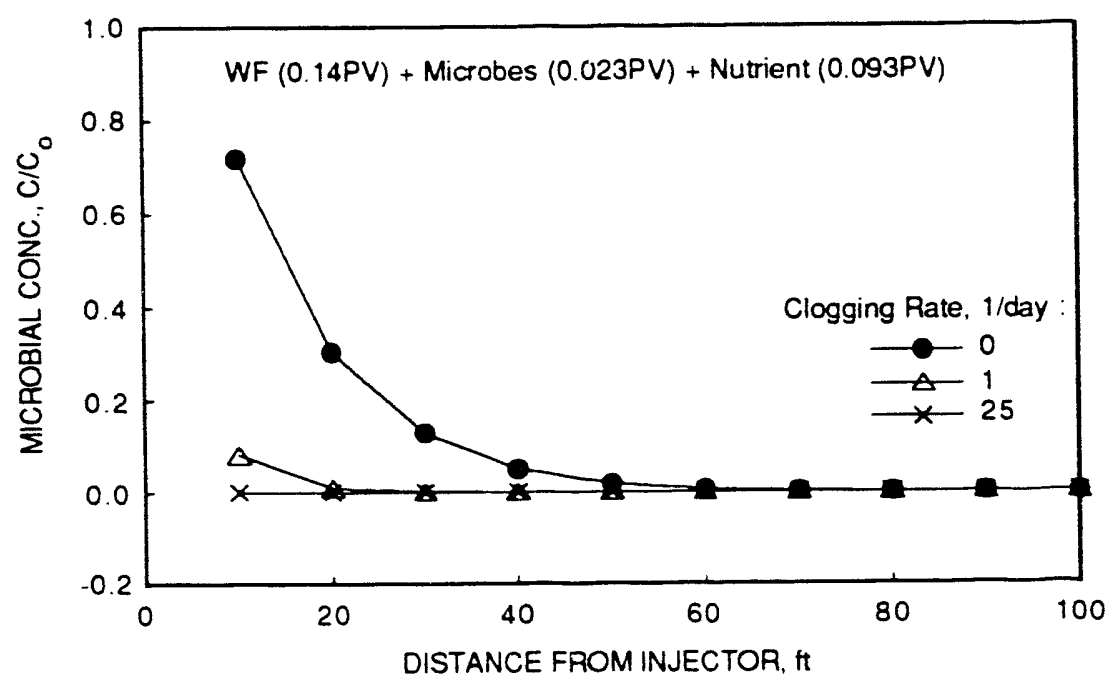

FIGURE 6. - Microbial profiles for reservoirs with various clogging rate constants.

The effect of chemotaxis on microbial transport is shown in Fig. 7. The microbial concentration profiles, simulated at three different values of chemotaxis coefficients $\left(k_{m}\right): 0,1$, and 3, respectively, were plotted together with the profile of the nutrient concentration. Because of the high concentration of nutrient close to the injection wellbore, a higher concentration of microbes is found close to the injector for microbes with a higher value of $k_{m}$ than those with lower values of $\mathrm{k}_{\mathrm{m}}$. At a distance of $10 \mathrm{ft}$ or deeper into the formation, on the other hand, a higher concentration is found for microbes with lower values of $\mathrm{k}_{\mathrm{m}}$. For the case studied, the microbial concentration for $k_{m}$ value of 0 is about three times as much as those with $k_{m}$ value of 3 when the distance is more than $20 \mathrm{ft}$ away from the injector.

Simulations of injection profile modification using microbial treatments were run on a twolayer cross section model. The top layer has a permeability of 1,000 md and pay thickness of $20 \mathrm{ft}$, whereas the bottom layer has a permeability of $100 \mathrm{md}$ and pay thickness of $10 \mathrm{ft}$. Five feet in the $x$-direction was used as the size for wellbore grids and grids next to the injection wellbore. The microbes and nutrients were introduced into the injection well in the model after water breakthrough from the high-permeability layer. The plugging of microorganisms to the wellbore next to the high-permeability layer diverts the injection water into the low-permeability layer 


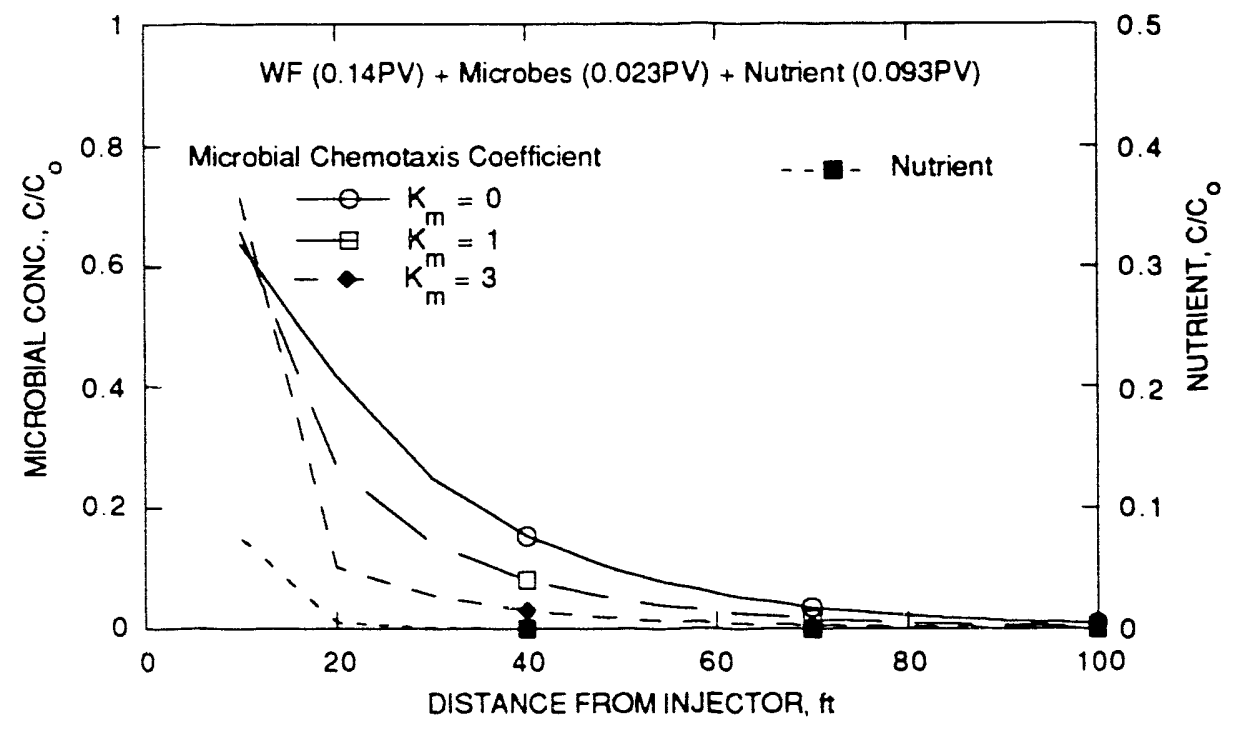

FIGURE 7. - Effect of chemotaxis coefficient $\mathrm{k}_{\mathrm{m}}$ on microbial concentration profile.

(Fig. 8). Compared to the case without microbial treatment, this results in a decrease of water-oilratio (Fig. 9) and, therefore, an increase of oil recovery during the waterflood. The clogging and declogging rate constants were assumed to be 25 and 37 day $^{-1}$, respectively, in models. The fractional injection of vater into the low-permeability layer drops during the later stage of waterflood due to microbial declogging and the cease of nutrient injection. These simulation runs indicate the feasibility of applying the microbial treatment to improve the injection profile in waterfloods.

Simulations were performed to study the effect of selective layer treatment in the microbial profile modification. The microbes were injected only into the high-permeability layer in the case of single-layer treatment. The selective treatment of the high-permeability layer is more effective in diverting the injected water into the low-permeability layer (Fig. 8). Fig. 9 shows the comparison of water-oil ratios from two-layer treatment and single-layer treatment. A more significant decrease in water-oil ratio was predicted by the model from the single-layer treatment than the two-layer treatment. 


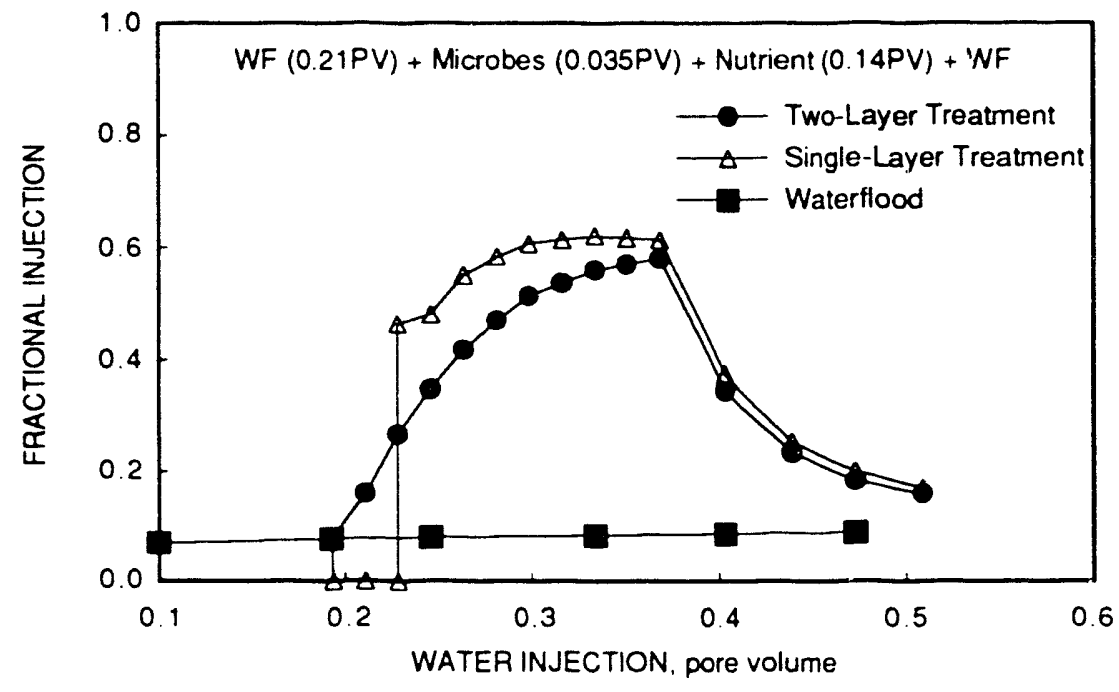

FIGURE 8. - Fractional injection into low-permeability layer.

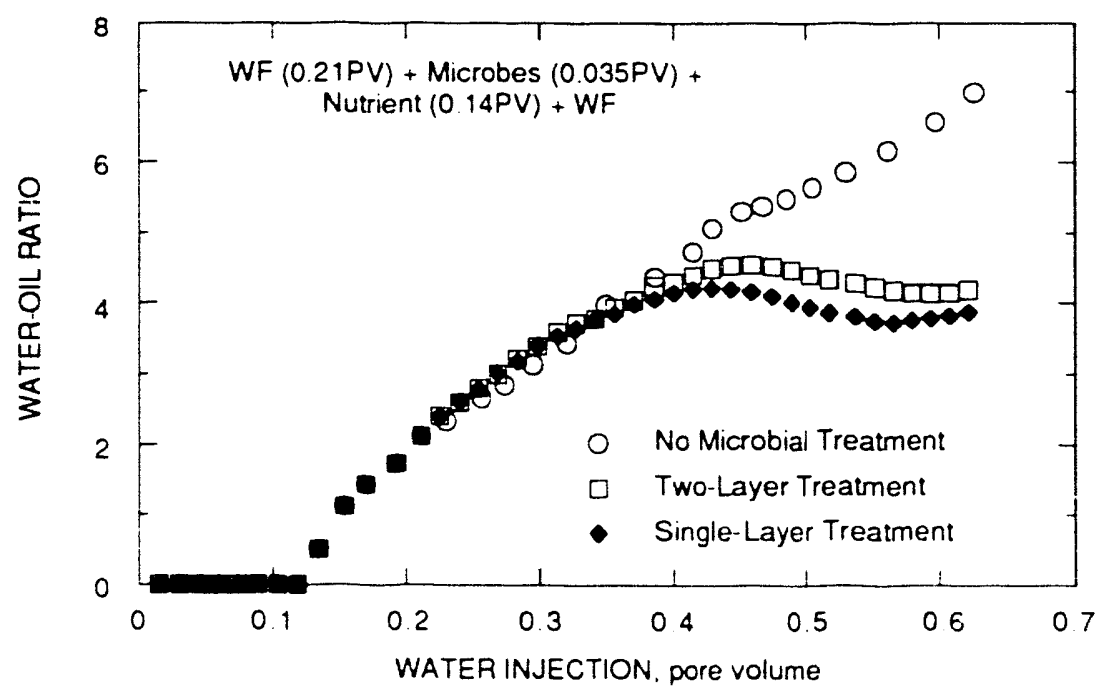

FIGURE 9. - Injection profile modification using microbial treatment. 


\section{CONCLUSIONS}

The following conclusions were drawn from this study:

1. A three-dimensional, three-phase, multiple-component simulator that includes all required mechanisms and transport phenomena of microbial systems in porous media can be used to predict the propagation of microbes and nutrients in porous media to design laboratory experiments and field operations in order to optimize injection strategies for improving oil recovery..

2. Laboratory experiments were successful in determining some of the input parameters of the microbial transport system for the developed mathematical model.

3. The simulator can be used to study the effects of adsorption, chemotaxis, and injection strategy on the transport process of the microbial system in porous media. Clogging or adsorption of microbes to a rock surface is critical to the transport of microorganisms in porous media.

\section{NOMENCLATURE}

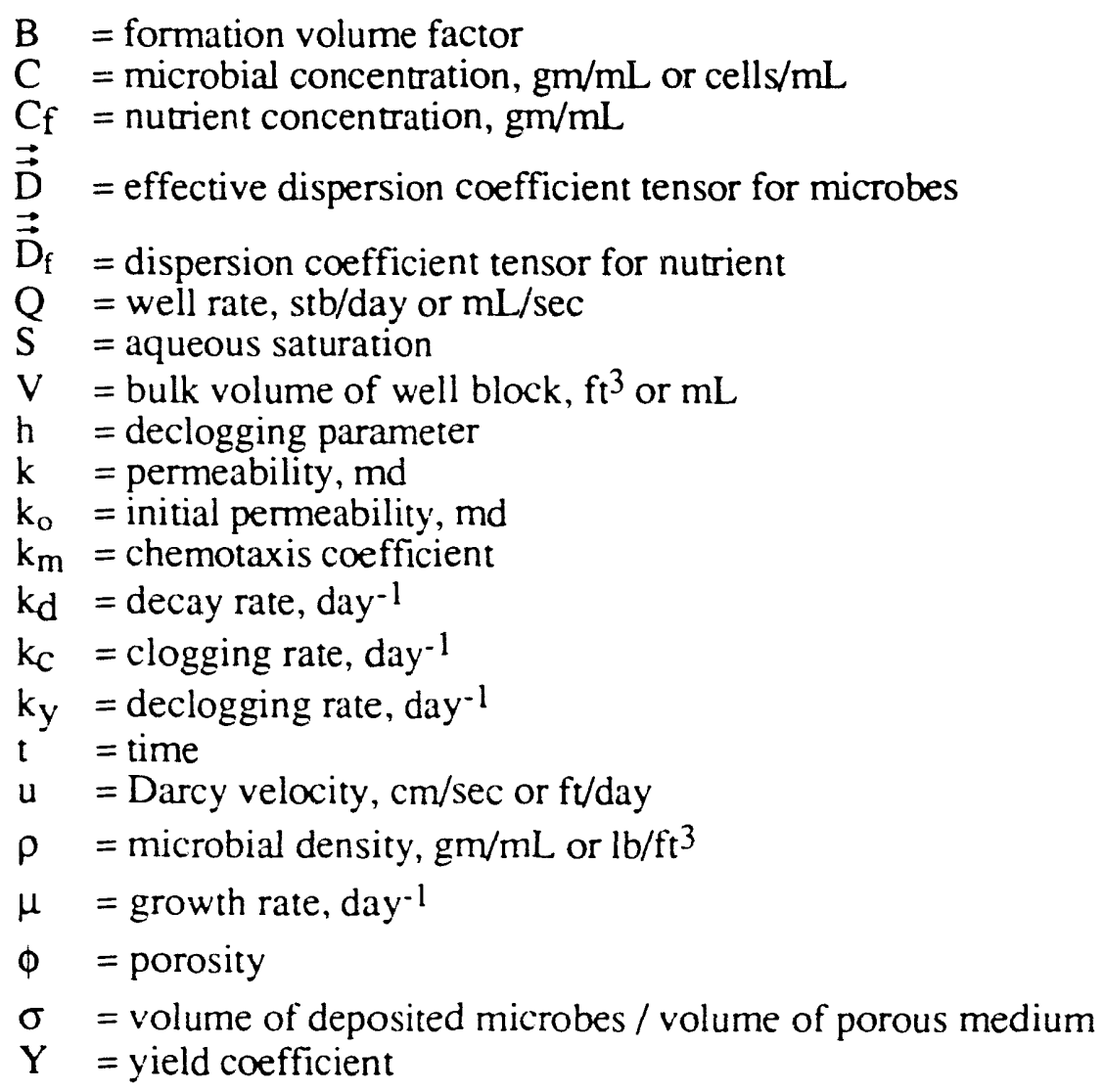




\section{REFERENCES}

1. Bryant, R. S. and T. E. Burchfield. Review of Niicrobial Technology for Improving Oil Recovery, SPE Reservoir Engineering, May 1989, pp. 151-154.

2. Bryant, R. S. and J. Douglas. Evaluation of Microbial Systems in Porous Media for EOR, SPE Reservoir Engineering, May 1988, pp. 489-495.

3. Hitzman, D. O. Review of Microbial Enhanced Oil Recovery Field Tests, Proceedings of the Symposium on Applications of Microorganisms to Petroleum Technology, NIPER-351, DE88001232, September, 1988.

4. Corapcioglu, M. Y. and A. Haridas. Transport and Fate of Microorganisms in Porous Media: A Theoretical Investigation. J. of Hydrology, v. 72, 1984, pp 149-169.

5. Dahlquist, F. W., P. Lovely, and D. E. Koshland, Jr. Quantitative Analysis of Bacterial Migration in Chemotaxis. Nature New Biology, v. 236, March 1972, pp 120-123.

6. Tien, C. and S. Wang. Dynamics of Adsorption Column with Bacterial Growth Outside Adsorbents, The Canadian J. of Chemical Engineering, v. 60, 363-376, June, 1982.

7. Kalish, P. J., J. A. Stewart, W. F. Rogers, and E.O. Bennett. The Effect of Bacteria on Sandstone Permeability, J. of Petroleum Technology, v. 16, 805-814, 1964.

8. Jang, L., M. M. Sharma, and T. F. Yen. The Transport of Bacteria in Porous Media and Its Significance in Microbial Enhanced Oil Recovery. Pres. at the 1984 SPE California regional Meeting in Long Beach, CA, April 11-13. SPE 12770.

9. Sarkar, A. K., M. M. Sharma, and G. Georgiou. Compositional Numerical Simulation of MEOR Processes. Development in Petroleum Science v. 31, paper no. R-21, Pres. at 1990 International Conference on Microbially Enhanced Oil Recovery, May 27 - June 1, 1990.

10. Islam, M. R. Mathematical Modeling of Microbial Enhanced Oil Recovery. Pres. at the 65th SPE Annual Conference at New Orleans, LA, September 23-26, 1990. SPE 20480.

11. Knapp, R. M. and F. Civan. Modeling Growth and Transport of Microorganisms in Porous Formations. Pres. at 1988 Meeting of International Association for Mathematics and Computers in Simulation at Paris, France.

12. Gaudy, A. F. Jr. and E. T. Gaudy. Microbiology for Environmental Scientists and Engineers, McGraw-Hill Book Co., 1980.

13. Chilingarian, G. V., J. Chang, and K. I. Bagrintseva. Emperical Expression of Permeability in terms of Porosity, Specific Surface Area, and Residual Water Saturation of Carbonate Rocks. J. of Petroleum Science and Engineering, vol. 4, pp. 317-322, 1990.

14. Fanchi, J. R., K. J. Harpole, S. W. Bujnowski, and H. B. Carroll, Jr. BOAST: A ThreeDimensional, Three-Phase Black Oil Applied Simulation Tool (Version 1.1). Volume I: Technical Description and Fortran Code. U. S. Dept. of Energy Report No. DOE/BC/10033-33, v. 1., Sept. 1982. 
15. Von Rosenberg, D. U. Methods for Numerical Solution of Partial Differential Equations. Elsevier, New York, N.Y., 1977. p. 56.

16. Chase, K. L., R. S. Bryant, T. E. Burchfield, K. M. Bertus, and A. K. Stepp. Investigation of Microbial Mechanisms for Oil Mobilization in Porous Media. Development in Petroleum Science v. 31, paper no. R-4, Pres. at 1990 International Conference on Microbially Enhanced Oil Recovery, May 27 - June 1, 1990. 

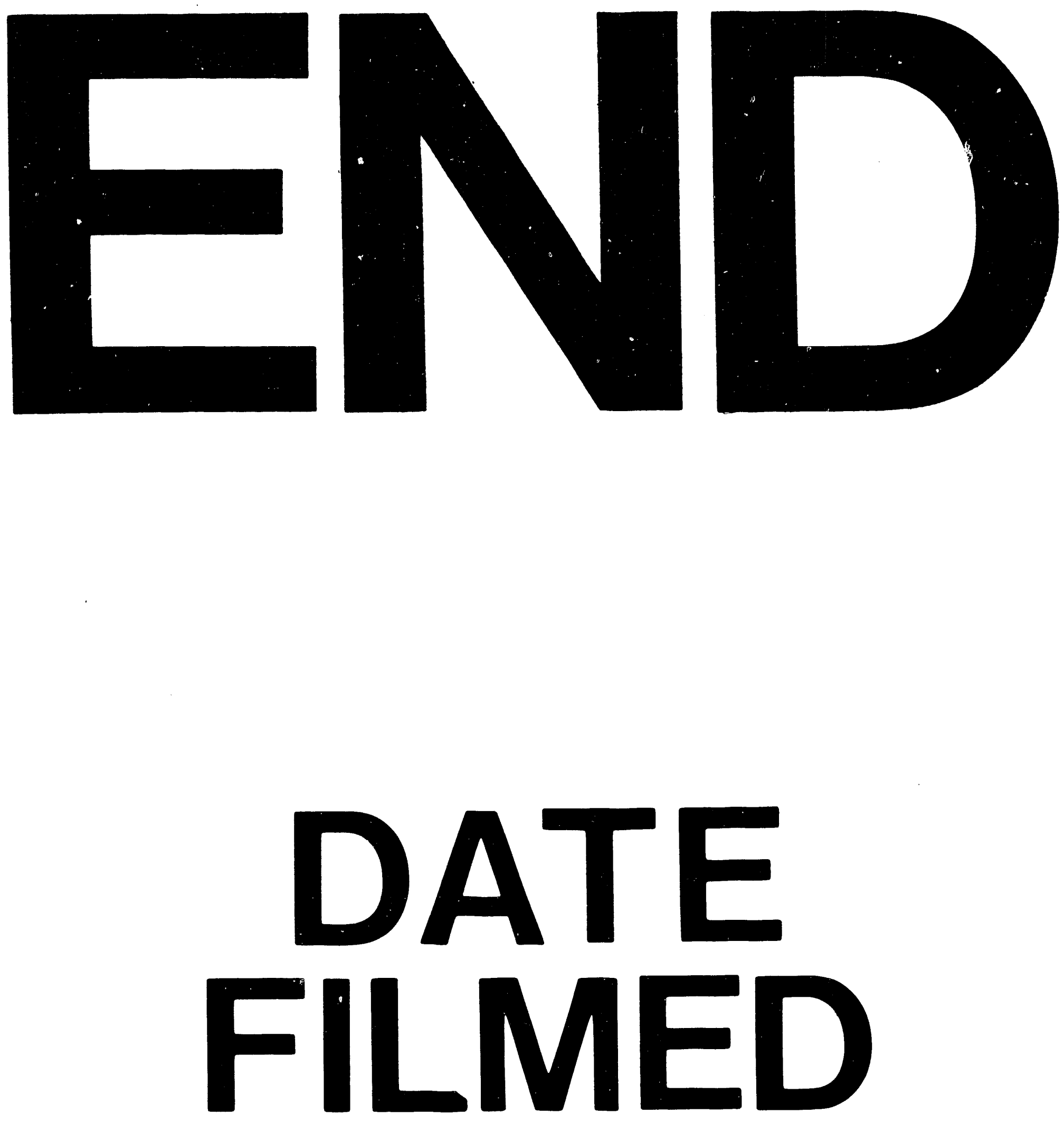

1

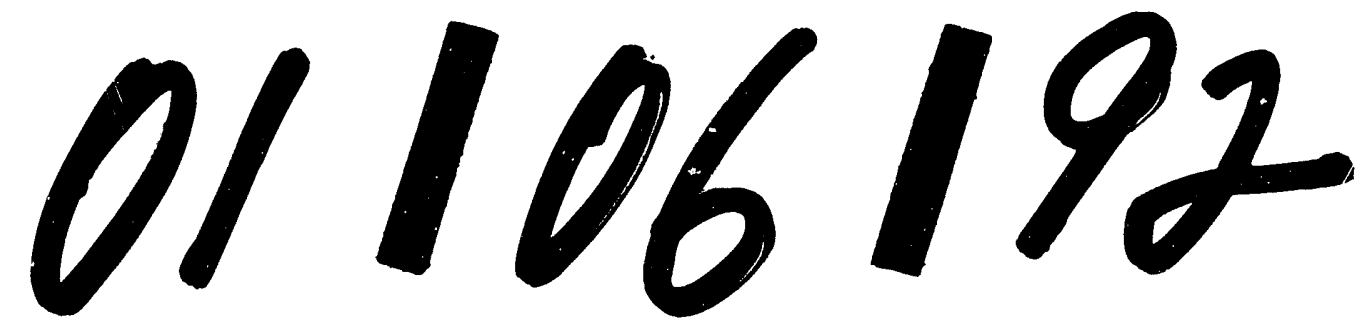


